\title{
Research Paper: Stress, Anxiety, and Depression Levels Among Healthcare Staff During the COVID-19 Epidemic
}

\author{
Zarintaj Hosseinzadeh-Shanjani ${ }^{1} \odot$, Khadijeh Hajimiri ${ }^{2} \odot$, Bahram Rostami $^{3} \odot$, Shokoufeh Ramezani $^{4} \odot$, Mohsen Dadashi $^{*} \odot$ \\ 1. Social Determinants of Health Research Center, Zanjan University of Medical Sciences, Zanjan, Iran. \\ 2. Department of Health education and promotion, school of public health, Social Determinants of Health Research Center, Zanjan University of Medi- \\ cal Sciences, Zanjan, Iran. \\ 3. Educational Development Center, Zanjan University of Medical Sciences, Zanjan, Iran. \\ 4. Department of Educational Sciences, Faculty of Educational Sciences and Psychology, University of Mohaghegh Ardabili, Ardabili, Iran \\ 5. Department of Clinical Psychology, Faculty of Medicine, Social Determinants of Health Research Center, Zanjan University of Medical Sciences, \\ Zanjan, Iran.
}

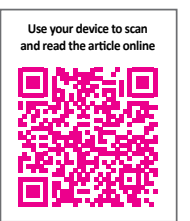

Citat on: Hosseinzadeh-Shanjani, Z., Hajimiri, Kh., Rostami, B., Ramezani, Sh., \& Dadashi, M. (2020). Stress, Anxiety, and Depression Levels Among Healthcare Staff During the COVID-19 Epidemic. Basic and Clinical Neuroscience, 11(2.Covid19), 163-170. http://dx.doi.org/10.32598/bcn.11.covid19.651.4

http://dx.doi.org/10.32598/bcn.11.covid19.651.4

\section{Article info:}

Received: 03 Apr 2020

First Revision: 05 Apr 2020

Accepted: 06 Apr 2020

Available Online: 10 Apr 2020

Keywords:

Stress, Anxiety, Depression, Medical staff, COVID-19

\begin{abstract}
A B S T RA C T
Introduction: In the Coronavirus Disease 2019 (COVID-19) pandemic, medical staff Are in direct contact with the patients and experience high work pressure. Direct contact with the patients could create some psychological problems in this group. Thus, the prevalence of such problems must be investigated in them. The present study aimed to determine the level of stress, anxiety, and depression among the healthcare staff in Zanjan City, Iran, during the COVID-19 epidemic.

Methods: This descriptive study has a cross-sectional design. The Sample of the study population consisted of 535 Staff healthcare members of Vali-e-Asr Hospital in Zanjan City, Iran. A sample of 200 of medical staff was randomly selected to participate in the present study. The required data were collected using the electronic version of Depression, Anxiety, Stress Scale (DASS) tool. Descriptive statistics, as well as the inferential statistics (the Pearson correlation coefficient, Spearman correlation coefficient, Phi, and Cramer's correlation tests), were used to analyze the obtained data in SPSS.

Results: The mean age of the study participants was 40.60 years. The mean values of depression, anxiety, and stress in study samples were $6.27,5.38$, and 8.41 , respectively. There was a significant relation between gender and variables of depression, anxiety, and stress. There was also an inverse relationship between stress and variables of educational level and age $(\mathrm{P}<0 / 05)$.

Conclusion: We found that our sample reported a normal degree of Depression, anxiety, and stress. The extent of stress induced by direct contact with patients was higher in female employees. Furthermore, with the increase in the education and age of the employees, their stress level decreased.
\end{abstract}

\section{* Corresponding Author: \\ Mohsen Dadashi, PhD.}

Address: Department of Clinical Psychology, Faculty of Medicine, Social Determinants of Health Research Center, Zanjan University of Medical Sciences, Zanjan, Iran.

Tel: +98 (12) 7433559

E-mail:mohsendadashi@zums.ac.ir 


\section{Highlights}

- According to WHO, the COVID-19 epidemic is considered as a severe acute respiratory syndrome.

- The COVID-19 epidemic is more serious than previous coronavirus outbreaks in humans.

- Personal hygiene and observing isolating suspected patients, social distance, disinfecting high-touch places are required to prevent the spread of this disease.

\section{Plain Language Summary}

The novel coronavirus outbreak which emerged in Wuhan City, China in December 2019 has raised attention around the world. The virus has currently spread to numerous countries. Personal hygiene and measures such as isolating suspected patients, social distance, disinfecting high-touch places, etc., could be highly effective in reducing and disconnecting the disease spread cycle. Psychosocial responses to the spread of the disease could include anxiety, depression, and social weakness. According ti evidence the exposure to infectious diseases was more frequent in the medical staff who experienced more fear, insecurity, and stress. Some findings indicated that fear, insecurity, and SARS-induced stigma were associated with psychological distress among some primary care providers. This study concluded that the spread of infectious diseases during epidemics could cause significant psychological stress, leading to adverse effects on the quality of life and mental health among the medical staff.

\section{Introduction}

he novel coronavirus outbreak which appeared in Wuhan City, China in December 2019 has raised attention around the world. It is referred to Severe Acute Respiratory Syndrome Coronavirus 2 (SARS-CoV-2) by the International Committee on Taxonomy of Viruses (ICTV) and COVID-19 by the World Health Organization (WHO) (Gorbalenya, 2020). According to global statistics, its morbidity is $3.4 \%$. The COVID-19 epidemic is more serious than previous coronavirus outbreaks in humans. Such data indicate the significant transmission potential of this virus (Mohammadzadeh, 2019). Therefore, this disease could have irreversible consequences for society and the health system, especially for at-risk groups, like patients with cardiovascular diseases (Mohammadzadeh, 2019). Besides, it could impose a high financial burden (diagnosis, long-term treatment, hospitalization, death of workforce, development of mental disorders, etc.) to the healthcare system (Mohammadzadeh, 2019).

The number of COVID-19 cases has reached 5854930 globally, of which 359903 individuals have lost their lives and 2540105 patients have recovered (Mohammadzadeh, 2019). The virus has currently spread to numerous countries around the world (World Health Organization, 2020). Iran is among the countries where the disease prevalence has been reported in most of its provinces. By May 29, cases 143849 individuals were infected and the total number of victims was 7627 cases, and the number of recovered was estimated to be 112988 cases in Iran. Of them, 2543 cases were being cared for critical conditions (Ministry of Health website, 2020).

Personal hygiene is required to prevent the spread of this disease. Measures, such as isolating suspected patients with COVID-19 disease, social distance, disinfecting high-touch places, etc. could be highly effective in reducing and disconnecting the disease spread cycle (World Health Organization, 2020). Any Research has indicated that the mortality rate of this virus in the elderly and individuals with underlying diseases (cardiovascular disease, cancer, immunodeficiency) is relatively high, compared to the healthy population (Tavakoli, Vahdat, \& Keshavarz, 2020).

In recent years, the spread of infectious diseases, including Severe Acute Respiratory Syndrome (SARS) and the Middle East Respiratory Syndrome (MERS) has challenged many societies (Liu, Yang, Zhang, Xu, Dou \& Zhang, 2020). The spread of infectious diseases causes biopsychological issues in society. Psychosocial responses to the spread of the disease could include anxiety, depression, social weakness, and decreased estimation of survival, an overestimation of the odds of infection, fostering inappropriate preventive measures, and an increase in demand for healthcare (Koh et al., 2005; Rosling \& Rosling 2003). The results of a longitudinal study in patients with SARS revealed that psychological and behavioral prob- 
lems, anxiety, or depression were common in the early stages of recovery among the patients. This condition improves over time in most cases (Wu, Chan, \& Ma, 2005).

The evidence suggests that exposure to infectious diseases was more frequent in the medical staff who experienced more fear, insecurity, and stress in the workplace. One study found that healthcare workers who performed tasks related to patients with MERS obtained a high score on the whole scale and subscales of the Holmes and Rahe stress scale at the time of the MERS outbreak (Lee, Kang, Cho, Kim, \& Park, 2018). Another study reported that the average General Health, physical Health, anxiety, and social functioning in general practitioners was significantly high. Such findings indicated that fear, insecurity, and SARS-induced stigma were associated with psychological distress among some primary care providers (Verma, Mythily, Chan, Deslypere, Teo, \& Chong, 2004).

Chen, Chou, Huang, Wang, Liu, \& Ho (2006) argued that the level of anxiety and depression in nursing staff has significantly decreased over time and by using the SARS prevention program. Health measures are required to prevent the spread of this disease. Measures, such as isolating suspected patients with COVID-19 disease, social distance, disinfecting high-touch places, and so on could be highly effective in reducing and disconnecting the disease spread cycle. Research has indicated that the mortality rate of this virus in the elderly and individuals with underlying diseases (cardiovascular disease, cancer, immunodeficiency) is relatively high, compared to the healthy population (Tavakoli, Vahdat, \& Keshavarz, 2020).

Zanjan Province is one of the provinces where COVID-19 infected many people with 1237 reported positive cases so far. However, 1023 people were discharged from the province's hospitals with full recovery, and 138 patients died as a result of the disease (Zanjan University of Medical Sciences website, 2020). Due to the social distancing plan, hospitalizations from other cities in this province are very rare and the prevalence of the disease is declining (Zanjan University of Medical Sciences website, 2020). Also, the spread of infectious diseases during epidemics could cause significant psychological stress, leading to adverse effects on the quality of life and mental health of the medical staff.

Accordingly, the development of psychological support programs for healthcare workers during the outbreak of infectious diseases is of significant importance. Therefore, the present study aimed to evaluate the level of stress, anxiety, and depression among hospital staff and those accompany- ing a patient in Vali-e-Asr Hospital (a treatment center for patients with COVID-19 disease) in Zanjan City, Iran.

\section{Methods}

This descriptive study has a cross-sectional design. It was conducted from March 2020 to May 2020. The study population consisted of 535 healthcare members of Vali-e-Asr Hospital in Zanjan City, Iran. The sample size was estimated to be 224 using the Cochran's formula. Finally, 200 questionnaires were completed by the study participants and entered the statistical analysis process. In this study, due to the availability of the sampling framework, accessible sampling method was used to select the study participants. Moreover, the study subjects were selected using the staff list and random numbers. The inclusion criteria included employment in the hospital and a willingness to participate in the study.

The required data were collected using the electronic version of Depression, Anxiety, Stress Scale (DASS). Demographic data form, including age, educational level (MD/Specialist and above, Professional Doctorate, Diploma, Associate degree, BA, MA), marital status (Married, Single), gender (Female, Male), organizational position (Nurse, Physician, Administrative officer, Laboratory and radiological force, Service force), and type of employment (Contract-based, Official, Company-based, Internship, Contract) was used to collect the demographic data of the study samples.

The 21-item DASS was developed by Lovibond et al. in 1995 to measure stress and anxiety. The DASS-21 comprises 3 components: stress, anxiety, and depression. Each has 7 scales, and the final score of each part is obtained by summing the scores of the related questions. Each item scores from 0 (absolutely disagree) to 3 (absolutely agree) (Lovibond \& Lovibond, 1995).

Antony, Bieling, Cox, Enns, \& Swinson, (1998) performed a factor analysis on the scale and supported the presence of three factors: depression, anxiety, and stress. They concluded that $68 \%$ of the total scale variance is explained by these three factors. The Cronbach alpha coefficients for these factors were calculated as 0.97, 0.92, and 0.95 , respectively. Additionally, the results of calculating the correlation between the factors in Anthony et al. study highlighted these correlations: a correlation coefficient of 0.48 between the two factors of depression and stress, a correlation coefficient of 0.53 between anxiety and stress, a correlation coefficient of 0.53 between anxiety and stress, and a correlation coefficient of 0.28 
Table 1. The demographic characteristics of the investigated healthcare staff

\begin{tabular}{|c|c|c|}
\hline \multicolumn{2}{|r|}{ Variable } & \multirow{2}{*}{$\begin{array}{c}\text { No. (\%) } \\
160(80)\end{array}$} \\
\hline \multirow{3}{*}{ Gender } & Female & \\
\hline & Male & $40(20)$ \\
\hline & Total & $200(100)$ \\
\hline \multirow{3}{*}{ Marital status } & Married & $162(81)$ \\
\hline & Single & $38(19)$ \\
\hline & Total & $200(100)$ \\
\hline \multirow{7}{*}{ Educational level } & MD./Specialist and above & $48(24)$ \\
\hline & PhD. & $10(5)$ \\
\hline & Diploma & $8(4)$ \\
\hline & Associate degree & $9(4.5)$ \\
\hline & Bachelor's degree & $96(48)$ \\
\hline & Master's degree & $29(14)$ \\
\hline & Total & $200(100)$ \\
\hline \multirow{6}{*}{ Type of employment } & Contract-based & 29 (14.5) \\
\hline & Official & $89(44.5)$ \\
\hline & Company-based & $14(7)$ \\
\hline & Internship & 35 (17.5) \\
\hline & Contract & $33(16.5)$ \\
\hline & Total & $200(100)$ \\
\hline \multirow{6}{*}{$\begin{array}{l}\text { Organizational posi- } \\
\text { tion }\end{array}$} & Nurse & $94(47)$ \\
\hline & Physician & $43(21.5)$ \\
\hline & Administrative officer & $24(12)$ \\
\hline & Laboratory and radiological force & $24(12)$ \\
\hline & Service force & $15(8.5)$ \\
\hline & Total & $200(100)$ \\
\hline
\end{tabular}

NEUR JSCIENCE

between anxiety and depression (Antony, Bieling, Cox, Enns, \& Swinson, 1998).

The reliability and validity of this questionnaire have been investigated by Samani and Jokar in Iran (Asghari Moghaddam, Saed, Dibajnia \& Zangeneh 2008). Its testretest reliabilities for depression, anxiety, and stress were reported as $0.80,0.76$, and 0.77 , respectively. Its Cron- bach alpha coefficients for depression, anxiety, and stress were computed as $0.81,0.74$, and 0.78 , respectively. For examining the validity of this scale, confirmatory factor analysis method and the main component technique were implemented. In the present study, the scale's face validity was examined by the Professors of Psychology and Research Methods. Furthermore, the internal consis- 
Table 2. Descriptive characteristics of the study variables in the explored subjects

\begin{tabular}{ccccc}
\hline Variable & No. & Min. & Max. & Mean \pm SD \\
\hline Age, y & 200 & 23 & 58 & $40.60 \pm 10.153$ \\
Depression & 200 & 2 & 21 & $6.270 \pm 5.550$ \\
Anxiety & 200 & 1 & 19 & $5.385 \pm 5.028$ \\
Stress & 200 & 1 & 21 & $8.415 \pm 5.773$ \\
\hline
\end{tabular}

Table 3. The relationship between depression, anxiety, and stress and the demographic characteristics of the explored subjects

\begin{tabular}{|c|c|c|c|c|c|c|c|}
\hline Variable & Index & Gender & $\begin{array}{l}\text { Marital } \\
\text { Status }\end{array}$ & $\begin{array}{l}\text { Educational } \\
\text { Level }\end{array}$ & $\begin{array}{c}\text { Employment } \\
\text { Type }\end{array}$ & $\begin{array}{l}\text { Organizational } \\
\text { Position }\end{array}$ & Age \\
\hline \multirow{3}{*}{ 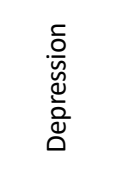 } & Correlation coefficient & -0.191 & 0.001 & 0.001 & 0.087 & 0.026 & -0.056 \\
\hline & Significance level & 0.007 & 0.985 & 0.985 & 0.228 & 0.729 & 0.558 \\
\hline & $N$ & 200 & 200 & 200 & 200 & 200 & 200 \\
\hline \multirow{3}{*}{$\begin{array}{l}\frac{\vec{v}}{\frac{0}{x}} \\
\frac{\vec{\alpha}}{4}\end{array}$} & Correlation coefficient & $-0.293^{*}$ & 0.037 & 0.037 & 0.063 & -0.025 & -0.199 \\
\hline & Significance level & 0.000 & 0.602 & 0.602 & 0.387 & 0.739 & 0.036 \\
\hline & $N$ & 200 & 200 & 200 & 200 & 200 & 200 \\
\hline \multirow{3}{*}{ 岕 } & Correlation coefficient & $-0.211^{* *}$ & -0.022 & -0.022 & 0.059 & 0.009 & -0.174 \\
\hline & Significance level & 0.003 & 0.752 & 0.752 & 0.417 & 0.906 & 0.069 \\
\hline & $N$ & 200 & 200 & 200 & 200 & 200 & 200 \\
\hline
\end{tabular}

tency of the questionnaire was obtained as 0.82 using the Cronbach alpha coefficient.

Descriptive indicators, as well as Pearson's correlation coefficient, Spearman correlation coefficient, Phi, and Cramer's correlation tests, were used to analyze the obtained data in SPSS.

\section{Results}

In total, 200 healthcare staff members of Hazrat Valie-Asr Hospital participated in the present study. Most study subjects were female employees, married, with a bachelor's degree. Nurses created the highest percentage of study participants (Table 1).

As per Table 2, the mean age of the study participants was 40.60 years. Their mean depression, anxiety, and stress scores were 6.27, 5.38, and 8.41, respectively, which fell within a healthy scope. In other words, depression, anxiety, and stress levels were normal in the studied medical staff.
The results of the correlation test between the three main components of the study with demographic variables revealed that depression, anxiety, and stress were associated with gender. Moreover, healthcare staffs' anxiety was related to their level of education and age $(\mathrm{P}<0.05)$ (Table 3).

\section{Discussion}

Our results suggested that depression, anxiety, and stress were at healthy levels in the explored medical staff caring for patients with COVID-19 disease. In other words, scores in the three main components of the study fell in the normal scope, indicating that Medical staff, including physicians, nurses, as well as administrative and laboratory staff, obtained normal degree in depression, anxiety, and stress during coronavirus epidemic. Considering that Medical staff are in close contact with the disease and are at the frontline of the fight against the disease, they are more prone to develop the disease. In one study, the prevalence rate of COVID-19 disease was reported to be $3.8 \%$ among medical staff. Although 
a reason for the high prevalence rate of it was unprotected contact with the patients, the high prevalence rate of this disease could be another reason for such findings. Therefore, corona-related healthcare staffs' stress, anxiety, and depression were expected to be high. However, in the present study, the level of these components was found to be normal.

The results of this research were inconsistent with those of Wu, Yang, Zhang, Xu, Dou, \& Zhang (2020), Li et al., (2015), and Wu et al., (2009) studies. Wu reported a high percentage of medical staff being exposed to the virus due to unprotected contact. Besides, the other two studies found a high rate of psychological conditions and social stigma among medical workers associated with Ebola and SARS (Wu \& McGoogan, 2020, Li et al., 2015, Wu et al., 2009). In addition to these issues, the use of protective clothing that makes treatment much harder difficult than normal conditions, as well as the fear of being infected and spreading the disease cause stress and anxiety for these employees (Liu, et al., 2020). However, it seems that one of the reasons for the healthy level of stress, anxiety, and depression in the explored employees is the undiscovered dimensions of COVID-19 disease during the study. Accordingly, at the beginning of the coronavirus epidemic in the country, all its dimensions were unclear to the individuals and even the medical staff. Thus, the protective protocols were not well observed among the medical staff.

Koh et al., (2005) researched the SARS epidemic and concluded that half of Singapore's healthcare workers suffered from stress and work pressure. Fifty-six percent of these employees, who were in direct contact with patients with SARS in Singapore, reported workrelated stress and 53\% demonstrated work pressure (Koh et al., 2005). In SARS epidemics in Hong Kong, medical staff reported a high percentage of work-related stress after direct contact with patients (Cheong \& Lee, 2004). Moreover, stress and anxiety were more prevalent among employees who had direct contact with patients with COVID-19, compared to the other employees, including office staff. Such data indicated that direct contact with the patient was a risk factor in exacerbating stress and anxiety among medical staff (Wu \& McGoogan, 2020). In China, where the disease was first detected, a high percentage of stress was reported among healthcare staff. However, in these studies, the stress of these employees was also compared with the general population, which revealed a significant difference in this area (Liu, et al., 2020).
In the present study, there was also a significant relationship between gender and variables of depression, anxiety, and stress. The female staff obtained higher scores in the three components, which was consistent with the findings of the Lai study. In the above-mentioned study, women also experienced high levels of stress in direct contact with the patient, and male employees' scores were lower than theirs. This result could be explained by the biopsychological characteristics of women as women are more vulnerable in the face of stressful events. Stress was also associated with education and age. As age and education increase, the stress felt by COVID-19 decreases. This could also be due to increased awareness and experience per increasing age and education. Thus, employees with awareness and experience about the disease demonstrated lower stress.

One study limitation was its conduct during the peak of the coronavirus epidemic when the medical staff faced high work pressure. The study participants completed the questionnaire with extensive limitations and delays. Besides, although a significant number of questionnaires were distributed among the study subjects, we encountered a drop in the sample. It is recommended that other psychological factors in medical staff be investigated and the relevant results are reported in future research.

The present study results indicated that the mean scores of depression, anxiety, and stress were below the cutting point among corona-related medical staff. Thus, these employees obtained normal levels in these components. Furthermore, female employees had higher stress levels, than male employees; as the education and age of employees increased, their stress level decreased. Although the status of the explored components was normal in the present study, it is essential to maintain the mental health of these employees in the face of COVID-19 disease to prevent a high frequency of stress, anxiety, and depression among medical staff in the similar conditions.

\section{Ethical Considerations}

\section{Compliance with ethical guidelines}

All procedures performed in the study were approved by the Ethics Research Committee (Code: IR.ZUMS. REC.1398.490). The study participants were allowed to discontinue participating in the study at any stage of the research. The research procedures were explained to them and their data remained confidential. 
Funding

This project was financially supported by Zanjan University of Medical Sciences (Code: IR.ZUMS. REC.1398.490).

Authors' contributions

All authors contributed equally in preparing all parts of the research.

\section{Conflict of interest}

The authors declared no conflict of interest.

Acknowledgments

The authors appreciate the management and staff of Hazrat Vali-e-Asr Hospital and all the contributing colleagues in this study.

\section{References}

Antony, M. M., Bieling, P. J., Cox, B. J., Enns, M. W., Swinson, R. P. (1998). Psychometric properties of the 42-item and 21-item versions of the Depression Anxiety and Stress scales in clinical groups and community sample. Psychological Assessment, 10, 176-81. [DOI:10.1037/1040-3590.10.2.176]

Asghari Moghaddam, M, Saed, F, Dibajnia, P, Zangeneh, J. (2008). A Preliminary Validation of the Depression, Anxiety and Stress Scales (DASS) in Non-clinical Sample. Clinical Psychology \& Personality, 1(31), 23-38.

Chen, R., Chou, K. R., Huang, Y. J., Wang, T. S., Liu, S. Y., Ho, L. Y. (2006). Effects of a SARS prevention programme in Taiwan on nursing staff's anxiety, depression and sleep quality: A longitudinal survey. International Journal of Nursing Studies, 43(2): 215-25. [DOI:10.1016/j.ijnurstu.2005.03.006] [PMID] [PMCID]

Cheong, D., \& Lee, C. (2004). Impact of severe acute respiratory syndrome on anxiety levels of front-line health care workers. Hong Kong Medical Journal, 10(5), 325-30.

Gorbalenya, A. E. (2020). Severe acute respiratory syndromerelated coronavirus-The species and its viruses, a statement of the Coronavirus Study Group. BioRxiv. [Published Online] [DOI:10.1101/2020.02.07.937862]

Koh, D., Lim, M, K., Chia, S. E., Ko, S. M., Qian, F., \& NG, V., et al., (2005). Risk Perception and Impact of Severe Acute Respiratory Syndrome (SARS) on Work and Personal Lives of Healthcare Workers in Singapore What Can We Learn? Medical Care, 2005, 676-82. [DOI:10.1097/01.mlr.0000167181.36730. $\mathrm{cc}][\mathrm{PMID}]$

Lee, S. M., Kang, W. S., Cho, A. R., Kim, T., \& Park, J. K. (2018) Psychological impact of the 2015 MERS outbreak on hospital workers and quarantined hemodialysis patients. Compr Psychia- try, 87, 123-7. [DOI:10.1016/j.comppsych.2018.10.003] [PMID] [PMCID]

Li, L., Wan, C., Ding, R., Liu, Y., Chen, J., \& Wu, Z., et al., (2015). Mental distress among Liberian medical staff working at the China Ebola Treatment Unit: A cross sectional study. Health And Quality of Life Outcomes, 13(1), 156. [DOI:10.1186/s12955015-0341-2] [PMID] [PMCID]

Liu, C. Y., Yang, Y. Z., Zhang, X. M., Xu, X., Dou, Q. L., \& Zhang, W. W. (2020). The prevalence and influencing factors for anxiety in medical workers fighting COVID-19 in China: A cross-sectional survey. Retrieved from: SSRN 3548781. [DOI:10.1101/2020.03 $.05 .20032003]$

Liu, X., Shao, L., Zhang, R., Wei, Y., Li, J., Wang, C., \& Hong, X., et al., (2020). Perceived social support and its impact on psychological status and quality of life of medical staffs after outbreak of sars-cov-2 pneumonia: A cross-sectional study. Retrieved from https://ssrn.com/abstract=3541127 or http:/ / dx.doi.org/10.2139/ssrn.3541127.

Lovibond, P. F., \& Lovibond, S. H.(1995). The structure of negative emotional states: comparison of the Depression Anxiety Stress Scales (DASS) with the beck depression and anxiety inventories. Behaviour Research and Therapy, 33, 335-43. [DOI:10.1016/0005-7967(94)00075-U]

Ministry of Health website. (2020). Covid prevalence statistics 19. Retrieved from https://www.behdasht.gov.ir

Mohammadzadeh, A. R. (2019). The effectiveness of electronic health care and pharmacy monitoring program to prevent covid-19 (sars-cov-2 virus) and reduce of corona disease anxiety after bypass surgery-a pilot study, quarterly. Journal of Nursing Management (IJNV) Original Article, 8(3)26-34

Rosling, L., \& Rosling, M. (2003). Pneumonia causes panic in Guangdong province. The BM], 326(7386), 416. [DOI:10.1136/ bmj.326.7386.416] [PMID] [PMCID]

Tavakoli, A., Vahdat, K., Keshavarz, M. (2020). Novel Coronavirus Disease 2019 (COVID-19): An emerging infectious disease in the 21st century. Iranian South Medical Journal, 22(6), 432-50. [DOI:10.29252/ismj.22.6.432]

Verma, S., Mythily, S., Chan, Y. H., Deslypere, J. P., Teo, E. K., \& Chong, S. A. (2004). Post-SARS psychological morbidity and stigma among general practitioners and traditional Chinese medicine practitioners in Singapore. Ann Acad Med Singapore, 33(6), 743-8.

World Health Organization. (2020). Coronavirus disease (COVID-19) pandemic. Geneva, Switzerland: World Health Organization. https://www.who.int/emergencies/diseases/novelcoronavirus-2019?gclid=EAIaIQobChMIqOaRx8SD6gIVGO DtCh1jyA_wEAAYASAAEgJ-2vD_BwE

Wu, K. K., Chan, S. K., Ma, T. M. (2005). Posttraumatic stress, anxiety, and depression in survivors of Severe Acute Respiratory Syndrome (SARS). Journal of Traumatic Stress, 18(1), 39-42. [DOI:10.1002/jts.20004] [PMID] [PMCID]

Wu, P., Fang, Y., Guan, Z., Fan, B., Kong, J., \& Yao, Z., et al. (2009). The psychological impact of the SARS epidemic on hospital employees in China: Exposure, risk perception, and altruistic acceptance of risk. The Canadian Journal of Psychiatry, 54(5), 302-11. [DOI:10.1177/070674370905400504] [PMID] [PMCID] 
Wu, Z., McGoogan, J. M. (2020). Characteristics of and important lessons from the Coronavirus Disease 2019 (COVID-19) outbreak in China: Summary of a report of 72314 cases from the Chinese Center for Disease Control and Prevention. Journal of the American Medical Association. [Published Online] [DOI:10.1001/jama.2020.2648]

Zanjan University of Medical Sciences. (2020). Covid prevalence statistics 19. Retrieved from https://www.zums.ac.ir. 